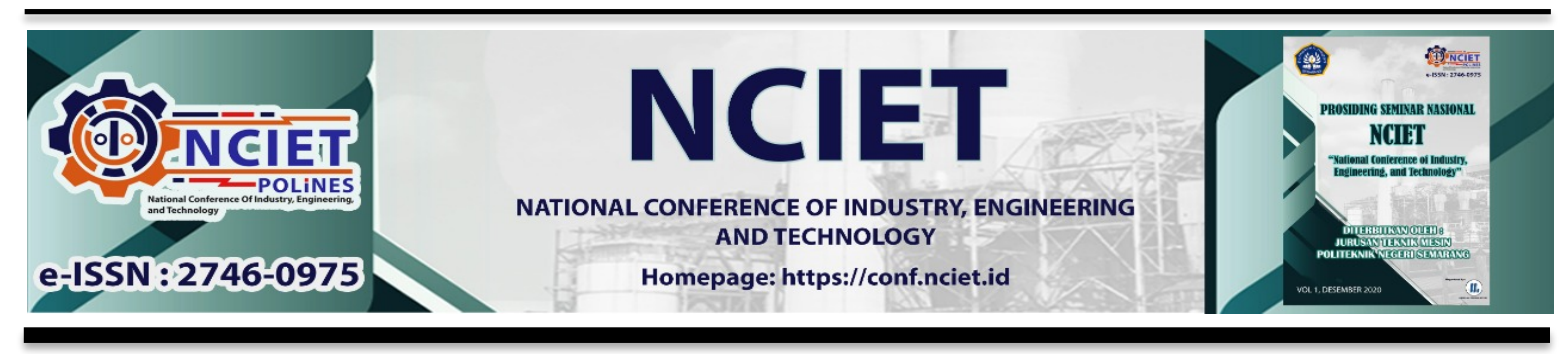

Prosiding Seminar Nasional NCIET Vol.1 (2020) B500-B508

$1^{\text {st }}$ National Conference of Industry, Engineering and Technology 2020,

Semarang, Indonesia.

\title{
ANALISIS PENGUKURAN HARMONISA TEGANGAN DAN ARUS LISTRIK PADA PT. EASTERN PEARL FLOUR MILLS MAKASSAR
}

\author{
Sofyan, Sarma Thaha, Fibrianti Ginting* \\ Program Studi Teknik Elektro, Politeknik Negeri Ujung Pandang \\ Jl. Perintis Kemerdekaan KM. 10, Makassar, 90245 \\ *E-mail: fibriantiginting@gmail.com
}

\begin{abstract}
Abstrak
Penggunaan beban non-linier memberikan dampak negatif seperti panas berlebih pada kabel penghantar, penurunan faktor daya, dan tingginya rugi-rugi. Dengan mengetahui nilai harmonisa tegangan dan arus listrik pada transformator $20 \mathrm{kV}$ di PT. Eastern Pearl Flour Mills Makassar, maka akan diketahui nilai rugi-rugi dan nilai efisiensi dari transformator. Setelah dilakukan pengambilan data, dilakukan analisis kesesuaian harmonisa tegangan dan arus terhadap standar IEEE 519 Tahun 1992, besarnya nilai rugi-rugi dan nilai efisiensi transformator. Nilai harmonisa tegangan masih dibawah standar 5\% yaitu ada pada rentang 2,5\% - 2,9\%. Nilai arus harmonisa masih dibawah standar $8 \%$ dan $12 \%$ yaitu pada rentang $2,1 \%-2,5 \%$. Sebelum harmonisa efisiensi transformator adalah $98,64 \%$ dan setelah harmonisa menjadi $98,58 \%$.
\end{abstract}

Kata Kunci: harmonisa; THD; losses; efisiensi; IEEE 519-1992.

\section{PENDAHULUAN}

Dalam Sistem Tenaga Listrik dikenal beban linier dan non-linier. Beban linier adalah beban yang memberikan bentuk gelombang keluaran yang linier artinya arus yang mengalir sebanding dengan impedensi dan perubahan tegangan. Beban linier ini tidak memberikan dampak yang buruk pada perubahan gelombang arus maupun tegangan. Resistor (R) merupakan beban linier tersebut. Beban-beban di industri yang bersifat non linear seperti motor listrik, kendali kecepatan motor, inverter, rectifier, converter. Transformator dikenal sebagai sumber harmonik jika dioperasikan di atas batas arus yang diijinkan sehingga menyebabkan saturasi.

Harmonik yang mengalir pada sistem tenaga dapat menyebabkan berbagai permasalahan seperti meningkatnya rugi-rugi daya, pemanasan berlebih pada peralatan, rendahnya efisiensi, unjuk kerja peralatan tertentu yang sensitif terhadap distorsi harmonik menjadi turun, dan lain-lain. Pengaruh harmonik tersebut secara teknis maupun ekonomis sangat 
merugikan sistem tenaga listrik. Oleh karena itu, untuk mengantisipasi permasalahan yang timbul akibat munculnya distorsi harmonik tersebut, terlebih dahulu perlu dilakukan pengukuran terhadap besarnya kandungan harmonik pada suatu sistem tenaga.

Pengukuran dapat dilakukan dengan menggunakan peralatan khusus yang mampu mengetahui besarnya kandungan harmonik. Permasalahannya, harga peralatan untuk mengukur kandungan harmonik tersebut relatif mahal, sehingga tidak semua industri (khususnya industri skala menengah/kecil) yang mempunyai permasalahan dengan distorsi harmonik mampu membeli peralatan tersebut dalam rangka mengatasi permasalahannya. Berdasarkan hal tersebut, maka rumusan masalah penelitian ini adalah:

1. Bagaimana nilai harmonisa tegangan dan arus listrik pada Transformator Distribusi 20 kV di PT Eastern Pearl Flour Mills Makassar?

2. Bagaimana efisiensi transformator distribusi $20 \mathrm{kV}$ di PT. Eastern Pearl Flour Mills Makassar sebelum dan setelah harmonisa?

Beberapa penelitian yang telah dilakukan sebelumnya juga membahas tentang harmonisa tegangan dan arus listrik seperti berikut:

1. I. F. Koswara (2010) dengan penelitian berjudul Analisis Pengaruh Hamronik Pada Transformator Daya Di Industri Semen. Berdasarkan penelitian yang dilakukan dapat disimpulkan bahwa keberadaan arus harmonik pada transformator daya berpengaruh terhadap besarnya nilai rugi-rugi transformator. Semakin tinggi total arus harmonik pada transformator (26,3\%) maka semakin tinggi pula rugi-rugi beban $(4404,66 \mathrm{~W})$.

2. W. A. A. Widiastra, I. W. Rinas dan I. W. Sukerayasa (2017) dengan Analisis Pengaruh Total Harmonic Distortion Terhadap Losses dan Efisiensi Transformator RSUD Kabupaten Klungkung. Berdasarkan penelitian yang dilakukan, peningkatan losses mempengaruhi nilai efisiensi transformator. Losses dan efisiensi transformator tanpa pengaruh harmonisa pada transformator yaitu sebesar 0,62 kW dan 99,654\%. Sementara losses dan efisiensi transformator setelah terpengaruh harmonisa sebesar $8,885 \mathrm{~kW}$ dan $95,048 \%$.

3. A. Dharmawansyah, dan M. Idrus (2016) dengan Analisis Harmonisa Tegangan dan Arus Listrik Pada PT. Eastern Pearl Flour Mills Makassar. Berdasarkan penelitian yang dilakukan, kondisi harmonisa tegangan dan arus pada PT. EPFM Makassar masih sesuai dengan standar yang diatur. THD arus masih berada di bawah standar maksimum yang ditentukan IEE 512-2014 yaitu 8\%-12\% dan Permen ESDM No. 04 Tahun 2009 yaitu $5 \%$. Sedangkan THD tegangan juga masih berada dibawah standar maksimum yang 
ditentukan dalam IEEE 512-2014 yaitu 8\% dan Permen ESDM No. 04 Tahun 2009 yaitu $5 \%$.

Penelitian ini bertujuan untuk mengetahui kesesuaian nilai harmonisa tegangan dan arus listrik terhadap standar IEEE 519 Tahun 1992 serta efisiensi transformator distribusi $20 \mathrm{kV}$ sebelum dan sesudah harmonisa di PT. Eastern Pearl Flour Mills Makassar.

\section{METODE PENELITIAN}

Pertama-tama dilakukan pengambilan data pengukuran menggunakan Nanovip Plus dan Mains Monitoring Instrument EMA 1101-DP. Analisis data dilakukan dengan cara membandingkan nilai hasil pengukuran arus dan tegangan harmonisa yang diambil selama 2 hari dengan standar IEEE 519 Tahun 1992. Kemudian dilakukan perhitungan losses transformator untuk mengetahui efisiensi transformator sebelum dan setelah harmonisa.

\section{HASIL DAN PEMBAHASAN}

A. Analisis Total Harmonic Distortion (THD) Tegangan

Tabel 1. Perbandingan hasil pengukuran THD tegangan dengan IEEE selama 2 hari

\begin{tabular}{cccc}
\hline Fasa & Standar IEEE & Hasil Pengukuran & Keterangan \\
\hline Hari & & & \\
Pertama & & & \\
$\mathrm{R}$ & $5 \%$ & $2,9 \%$ & dibawah standar \\
$\mathrm{S}$ & $5 \%$ & $2,8 \%$ & dibawah standar \\
$\mathrm{T}$ & $5 \%$ & $2,9 \%$ & dibawah standar \\
Hari Kedua & & & dibawah standar \\
$\mathrm{R}$ & $5 \%$ & $2,5 \%$ & dibawah standar \\
$\mathrm{S}$ & $5 \%$ & $2,5 \%$ & dibawah standar \\
$\mathrm{T}$ & $5 \%$ & $2,5 \%$ & \\
\hline
\end{tabular}

Sumber: Data primer yang diolah.

Berdasarkan Tabel 1. Dapat dilihat bahwa nilai harmonisa tegangan pada ketiga fasa selama 2 hari berada dibawah standar harmonisa tegangan menurut IEEE 519-1992. 
B. Analisis Total Harmonic Distortion (THD) Arus

Untuk membandingkan hasil pengukuran dengan standar yang ada, maka terlebih dahulu dilakukan penentuan standar THD arus (Isc) yaitu 38800,42 A

Tabel 2. Perbandingan hasil pengukuran THD arus dengan IEEE selama 2 hari

\begin{tabular}{|c|c|c|c|c|c|}
\hline Fasa & IL & Isc/IL & Standar IEEE & $\begin{array}{c}\text { Hasil } \\
\text { Pengukuran }\end{array}$ & Keterangan \\
\hline \multicolumn{6}{|l|}{ Hari } \\
\hline \multicolumn{6}{|l|}{ Pertama } \\
\hline $\mathrm{R}$ & 933 & 41,6 & $8 \%$ & $2,5 \%$ & $\begin{array}{l}\text { dibawah } \\
\text { standar }\end{array}$ \\
\hline S & 840 & 46,2 & $8 \%$ & $2,1 \%$ & $\begin{array}{l}\text { dibawah } \\
\text { standar }\end{array}$ \\
\hline $\mathrm{T}$ & 864 & 44,9 & $8 \%$ & $2,4 \%$ & $\begin{array}{l}\text { dibawah } \\
\text { standar }\end{array}$ \\
\hline \multicolumn{6}{|c|}{ Hari Kedua } \\
\hline $\mathrm{R}$ & 810 & 47,9 & $8 \%$ & $2,3 \%$ & $\begin{array}{l}\text { dibawah } \\
\text { standar }\end{array}$ \\
\hline S & 680 & 57,05 & $12 \%$ & $2,3 \%$ & $\begin{array}{l}\text { dibawah } \\
\text { standar }\end{array}$ \\
\hline $\mathrm{T}$ & 800 & 48,5 & $8 \%$ & $2,1 \%$ & $\begin{array}{c}\text { dibawah } \\
\text { standar }\end{array}$ \\
\hline
\end{tabular}

Sumber: Data primer yang diolah.

Berdasarkan Tabel 2. Dapat dilihat bahwa nilai harmonisa arus pada ketiga fasa selama 2 hari berada dibawah standar harmonisa tegangan menurut IEEE 519 Tahun 1992.

C. Efisiensi Transformator

Sebelum melakukan perhitungan efisiensi transformator, terlebih dahulu dihitung losses transformator. Berdasarkan SPLN 50 : 1997 tentang spesifikasi transformator distribusi 2500 kVA, maka Total Losses sebelum harmonisa adalah:

$$
\begin{aligned}
\text { Total Losses } & =P_{i}+P_{c u} \\
\text { Total Losses } & =4000+25000 \\
\text { Total Losses } & =29000 \mathrm{~W}=29 \mathrm{~kW}
\end{aligned}
$$


Dengan menggunakan data sekunder, terlebih dahulu menghitung daya base 1 fasa:

$$
\begin{aligned}
& P_{\text {base } 1 \varnothing}=\frac{S \times \operatorname{Cos} \varphi}{\sqrt{3}} \\
& P_{\text {base 1Ø }}=\frac{2500 \times 0,85}{\sqrt{3}}=1226,9 \mathrm{~kW}
\end{aligned}
$$

Kemudian menghitung daya input seperti berikut:

$$
\begin{aligned}
& P_{\text {input }}=\sqrt{3} x V x I \times \cos \varphi \\
& P_{\text {input }}=2500 \mathrm{kVA} \times 0,85=2125 \mathrm{~kW}
\end{aligned}
$$

Tabel 3. Perhitungan Rugi Tembaga dan Rugi Eddy Current pada fasa $\mathrm{R}$

\begin{tabular}{ccccc}
\hline $\begin{array}{c}\text { Orde } \\
\text { Harmonik }\end{array}$ & $\mathrm{I}_{\mathrm{h}}(\mathrm{A})$ & $\mathrm{Ih}(\mathrm{p} . \mathrm{u})$ & $\mathrm{Ih} 2(\mathrm{p} . \mathrm{u})$ & Hasil Pengukuran \\
\hline 1 & 933 & 1 & 1 & 1 \\
3 & 5,599 & 0,0060 & $3,60128 \mathrm{E}-05$ & 0,000324115 \\
5 & 5,168 & 0,0055 & $3,06855 \mathrm{E}-05$ & 0,000767137 \\
7 & 4,738 & 0,0051 & $2,57843 \mathrm{E}-05$ & 0,001263431 \\
9 & 5,168 & 0,0055 & $3,06855 \mathrm{E}-05$ & 0,002485523 \\
11 & 3,876 & 0,0042 & $1,72606 \mathrm{E}-05$ & 0,002088529 \\
13 & 3,015 & 0,0032 & $1,04416 \mathrm{E}-05$ & 0,001764627 \\
15 & 3,015 & 0,0032 & $1,04416 \mathrm{E}-05$ & 0,002349356 \\
17 & 2,584 & 0,0028 & $7,67137 \mathrm{E}-06$ & 0,002217025 \\
19 & 2,584 & 0,0028 & $7,67137 \mathrm{E}-06$ & 0,002769363 \\
& TOTAL & & 1,000176655 & 1,016029106 \\
\hline
\end{tabular}

Berdasarkan Tabel 3. dapat dilihat hasil perhitungan Rugi Tembaga yaitu sebesar 1,000176655 p,u dan hasil perhitungan Rugi Eddy Current sebesar 1,016029106 p.u. Dari data rugi tersebut dapat dihitung Load Loss pada fasa $\mathrm{R}$ dengan menggunakan persamaan sebagai berikut :

$$
\begin{aligned}
& P_{L L}=\sum I_{h}^{2}+\left(\sum I_{h}^{2} x h^{2}\right) x P_{E C-R}(p, u) \\
& P_{L L \text { fasa } R}=1,000176655+1,016029106 \times 0,01
\end{aligned}
$$


$P_{\text {LLfasa R }}=2,02620576 p, u$

Pada Tabel 3. dapat dilihat peningkatan rugi tembaga sebesar 0,000176655 p.u atau dalam satu $\mathrm{kW}$ dapat dihitung sebagai berikut :

$$
\begin{aligned}
& P_{c u}(k W)=P_{c u}(p . u) x P_{\text {base } 1 \varnothing} \\
& P_{c u}(k W)=0,000176655 \text { p.u } x 1226,9 \mathrm{~kW} \\
& P_{c u}(k W)=0,2167326 \mathrm{~kW}
\end{aligned}
$$

Rugi Arus Eddy mengalami peningkatan sebesar 0,016029106 p.u atau dalam satuan kW dapat dihitung sebagai berikut :

$$
\begin{aligned}
& P_{e}(k W)=P_{e}(p . u) x P_{\text {base } 1 \emptyset} \\
& P_{e}(k W)=0,016029106 \text { p. u } x 1154,7 \mathrm{~kW} \\
& P_{e}(k W)=0,1966562 \mathrm{~kW}
\end{aligned}
$$

Dengan menggunakan persamaan Rugi Histerisi berikut:

$$
P_{h}=K_{h} \times \sum_{h=1}^{\infty} i_{h} \times h
$$

Maka, perhitungan Rugi Histerisis adalah sebagai berikut:

Tabel 4. Perhitungan Rugi Histerisis pada fasa $R$

\begin{tabular}{ccc}
\hline Orde Harmonik & $\mathrm{I}_{\mathrm{h}}(\mathrm{A})$ & $\mathrm{P}_{\mathrm{h}}(\mathrm{watt})$ \\
\hline 1 & 933 & 242,58 \\
3 & 5,599 & 4,36722 \\
5 & 5,168 & 6,1879 \\
7 & 4,738 & 8,62245 \\
9 & 5,168 & 12,0938 \\
11 & 3,876 & 11,0860 \\
13 & 3,015 & 10,1902 \\
15 & 3,015 & 11,7579 \\
17 & 2,584 & 11.4219 \\
19 & 2,584 & 12,7657 \\
& TOTAL & 89,0240
\end{tabular}


Berdasarkan Tabel 4. diperoleh Rugi Histerisis pada fasa R sebesar 89,0240 watt atau 0,089 kW. Sehingga Total Losses pada fasa R akibat harmonisa dapat dihitung sebagai berikut:

$$
\begin{aligned}
& \text { Losses fasa } R_{\text {fas }}=P_{c u}+P_{i} \\
& \text { Losses }_{\text {fasa } R}=P_{c u}+\left(P_{e}+P_{h}\right) \\
& \text { Losses }_{\text {fasa } R}=0,2167326 \mathrm{~kW}+(0,1966562 \mathrm{~kW}+0,089 \mathrm{~kW}) \\
& \text { Losses }_{\text {fasa } R}=0,502388782 \mathrm{~kW}
\end{aligned}
$$

Dengan menggunakan perhitungan yang sama, dihitung pula rugi-rugi pada fasa $\mathrm{S}$ dan fasa $\mathrm{T}$ yang dapat dilihat pada tabel berikut :

Tabel 5. Rugi-Rugi Fasa R, S, dan $T$

\begin{tabular}{ccccc}
\hline Fasa & $\mathrm{I}_{\mathrm{cu}}(\mathrm{kW})$ & $\mathrm{P}_{\mathrm{e}}(\mathrm{kW})$ & $\mathrm{P}_{\mathrm{h}}(\mathrm{kW})$ & Losses $(\mathrm{kW})$ \\
\hline $\mathrm{R}$ & 0,2039836 & 0,1850882 & 0,089 & 0,5023888 \\
$\mathrm{~S}$ & 0,0500216 & 0,0461820 & 0,044 & 0,1466085 \\
$\mathrm{~T}$ & 0,1930775 & 0,1677375 & 0,085 & 0,4683416 \\
& \multicolumn{2}{c}{ TOTAL } & & 1,1173389 \\
\hline
\end{tabular}

Pada Tabel 5. dapat dilihat total rugi-rugi akibat harmonisa pada ketiga fasa adalah $1,0644583 \mathrm{~kW}$. Untuk menghitung keseluruhan rugi-rugi pada transformator dapat dihitung sebagai berikut:

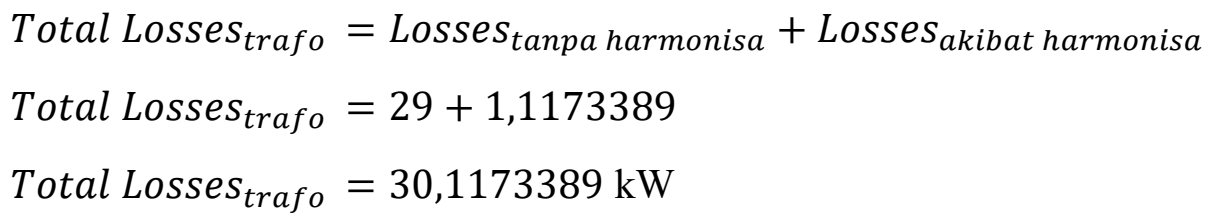

Setelah melakukan perhitungan losses, maka efisiensi transformator adalah sebagai berikut:

a. Efisiensi Sebelum Harmonisa

$$
\begin{aligned}
& \eta=\frac{P_{\text {in }}-\text { Losses sebelum harmonisa }}{P_{\text {in }}} \times 100 \% \\
& \eta=\frac{2125-29}{2125} \times 100 \% \\
& \eta=98,64 \%
\end{aligned}
$$


Berdasarkan perhitungan diperoleh $98,64 \%$ untuk efisiensi transformator tanpa harmonisa. Dikatakan tanpa harmonisa karena nilai rugi-rugi menggunakan ketetapan pada SPLN 50 mengenai spesifikasi transformator distribusi dan bukan hasil pengukuran nilai harmonisa. Dari $2125 \mathrm{~kW}$ daya yang masuk ke transformator, karena adanya rugi-rugi sebesar $29 \mathrm{~kW}$, maka hanya 98,64\% saja dari daya tersebut yang dapat digunakan untuk melayani beban.

b. Efisiensi Setelah Harmonisa

$$
\begin{aligned}
& \eta=\frac{P_{\text {in }}-\text { Losses setelah harmonisa }}{P_{\text {in }}} \times 100 \% \\
& \eta=\frac{2125-30,1174}{2125} \times 100 \% \\
& \eta=98,58 \%
\end{aligned}
$$

Untuk perhitungan efisiensi transformator setelah harmonisa dilakukan dengan menggunakan total losses pada transformator sehingga diperoleh 98,58\%. Terdapat selisih angka 0,06 antara efisiensi transformator sebelum harmonisa dan efisiensi transformator sesudah harmonisa. Dari $2125 \mathrm{~kW}$ daya yang diterima transformator, hanya 98,58\% dari daya tersebut yang dapat digunakan karena adanya rugi-rugi sebesar 30,1174 kW yang disebabkan oleh harmonisa. Dapat dilihat adanya pengaruh harmonisa dapat menimbulkan rugi-rugi, yang mana dikemudian hari dapat berubah menjadi energi panas yang berpotensi merusak peralatan. Adanya rugi-rugi akibat harmonisa juga dapat mempengaruhi efisiensi transformator. Efisiensi transformator menurun seiring dengan meningkatnya penambahan losses.

\section{KESIMPULAN}

Nilai harmonisa tegangan dan arus pada transformator masih dibawah standar IEEE 519 Tahun 1992. Standar harmonisa tegangan menurut IEEE 519 Tahun 1992 untuk transformator $20 \mathrm{kV}$ adalah $5 \%$ sementara nilai harmonisa tegangan pada transformator ada pada rentang 2,5\% - 2,9\%. Untuk standar harmonisa arus menurut IEEE 519 Tahun 1992 adalah $8 \%$ dan $12 \%$, sementara nilai harmonisa pada transformator ada pada rentang $2,1 \%$ 2,5\%. Meningkatnya nilai losses akan menurunkan nilai efisiensi transformator. Efisiensi transformator sebelum harmonisa adalah 98,64\%, sementara efisiensi transformator setelah terjadinya peningkatan nilai losses karna harmonisa adalah 98,58\%. 


\section{DAFTAR PUSTAKA}

Hakim, D. L., \& Surya, W. (2017). Analisis Harmonisa Tegangan dan Arus Listrik Di Gedung Direktorat TIK Universitas Pedidikan Indonesia. Universitas Pendidikan Indonesia.

Institute of Electrical and Electronics Engineering. (1992).

Koswara, I. F. (2010). Analisis Pengaruh Harmonik Pada Transformator Daya Di Industri Semen. Universitas Indonesia.

Siregar, R. S. (2017). Perhitungan Arus Netral, Rugi-Rugi, dan Efisiensi Transformator Distribusi 3 Fasa $20 \mathrm{kV} / 400 \mathrm{~V}$ di PT. PLN (Persero) Rayon Medan Timur Akibat Ketidakseimbangan Beban. Universitas Sumatera Utara.

Sugiarto, H. (2012). Kajian Harmonisa Arus dan Tegangan Listrik di Gedung Administrasi Politeknik Negeri Pontianak. Politeknik Negeri Pontianak.

Sujatmiko, A. (2010). Pengaruh Harmonisa Terhadap Kinerja Transformator Arus.Universitas Indonesia.

Widiastra, W. A. A., Rinas, I. W., Sukereyasa, I. W. (2017). Analisis Pengaruh Total Harmonic Distortion Terhadap Losses dan Efisiensi Transformator RSUD Kabupaten Klungkung. Universitas Udayana. 